\title{
Intestinal gastrointestinal stromal tumors presenting with gastrointestinal bleeding: different diagnostic modatities in three patients
}

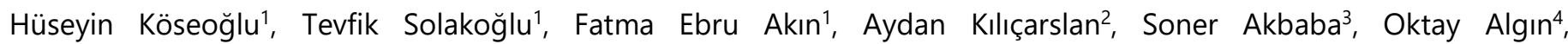
Naciye Şemnur Büyükaşık', Osman Ersoy ${ }^{5}$

\section{ABSTRACT}

Gastrointestinal stromal tumors (GIST) are mesenchymal tumors of the gastrointestinal tract. Although bleeding is one of the most symptoms seen in GIST, significant acute bleeding is an unusual finding. Here in, three cases with gastrointestinal bleeding due to GIST are presented. Of these patients one had duodenal, one had jejunal and the other had ileal GIST. The duodenal GIST was detected by endoscopy while the jejunal GIST was found by capsule endoscopy and the ileal GIST was shown on magnetic resonance enterography. All patients underwent surgery and the diagnoses of GISTs were confirmed by histopathological evaluation.

Keywords: capsule endoscopy, endoscopy, gastrointestinal bleeding, gastrointestinal stromal tumors, magnetic resonance enterography

\section{INTRODUCTION}

Gastrointestinal stromal tumors (GIST) are mesenchymal tumors of the gastrointestinal (GI) tract, which originate from interstitial cells of Cajal (1). GISTs represents $80 \%$ of mesenchymal GI tumors and $0.1-3 \%$ of all GI malignancies $(2,3)$. The small intestine is the second common location of GIST (30-40\%), after the stomach (50-60\%) (4). The clinical presentation of GIST is various: About $70 \%$ of the patients have symptoms and $30 \%$ are asymptomatic (4). Common symptoms are bleeding, abdominal pain and abdominal mass, but most patients have nonspecific symptoms like nausea, vomiting, abdominal discomfort, weight loss and early satiety. The level of $\mathrm{Gl}$ bleeding varies from asymptomatic occult bleeding to massive life-threatening hemorrhage (4).

Here we present 3 cases with bleeding from GISTs originating from small bowel, which is a rare origin for GI bleeding.

\section{CASE REPORTS}

\section{Case 1 (Ileal GIST)}

A 29-year-old man was admitted to the emergency room with hematochezia. Previously, he had Gl bleeding attacks for five times and the origin of bleeding was not detected. On initial laboratory analysis, hemoglobin level was $6.8 \mathrm{~g} / \mathrm{dL}$. The origin of bleeding could not be found with upper Gl endoscopy and total colonoscopy with ileal intubation. Abdominal computed tomography (CT) and Meckel's diverticulum scintigraphy showed no lesion with bleeding. Magnetic resonance enterography (MRE) was performed and a $5 \times 4 \mathrm{~cm}$ mass with heterogenous nature was observed at the distal ileum (Figure 1). Surgery was performed and a $6 \mathrm{~cm}$ exophytically growing mass was resected with a $2 \mathrm{~cm}$

\footnotetext{
1 Ataturk Research and Education Hospital, Department of Gastroenterology, Ankara, Turkey

2 Atatürk Research and Education Hospital, Department of Pathology, Ankara, Turkey

3 Atatürk Research and Education Hospital, Department of General Surgery, Ankara, Turkey

4 Atatürk Research and Education Hospital, Department of Radiology, Ankara, Turkey

5 Yildirim Beyazit University, Faculty of Medicine, Department of Gastroenterology, Ankara, Turkey
}

Correspondence: Hüseyin Köseoğlu

Ankara Ataturk Education and Research Hospital, Department of Gastroenterology, Ankara Turkey

E-mail: huseyinko@yahoo.com

Received: 24 Jan 2018, Accepted: 29 Mar 2018

(C) 2018 by the authors; licensee Modestum Ltd., UK. This article is an open access article distributed under the terms and conditions of the Creative Commons Attribution License (http://creativecommons.org/licenses/by/4.0/). 


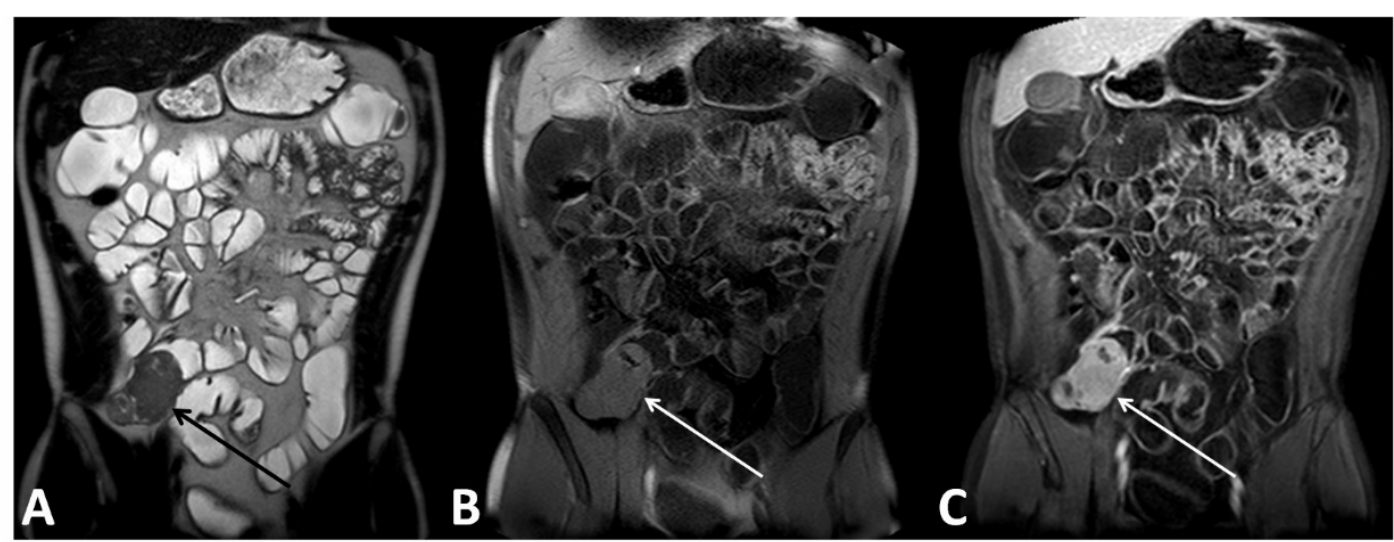

Figure 1: $M R$ enterography images of the patient. Coronal T2W (A), fat-suppressed T1W (B), and postcontrast fatsuppressed T1W (C) images show intraluminal solid mass in the distal ileum with contrast-material enhancement (arrows)

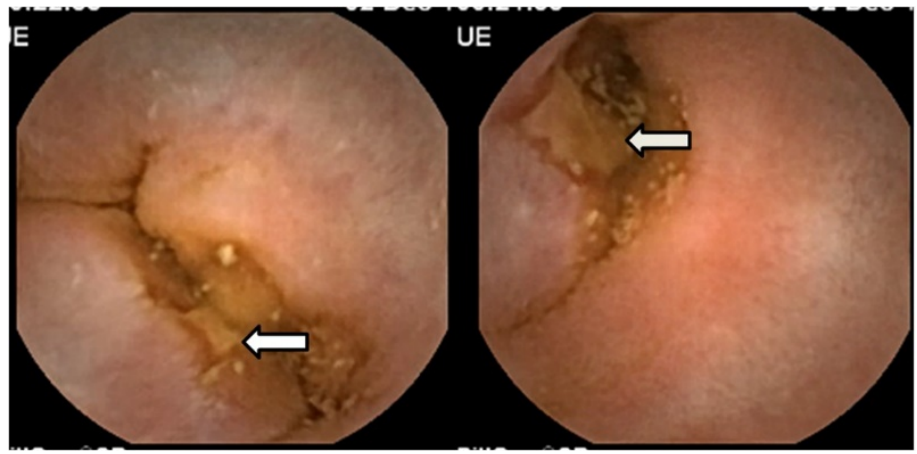

Figure 2: Capsule endoscopy revealed a submucosal mass with an ulcer (arrows) on it

margin. The macroscopic evaluation of the specimen showed a $6 \times 4 \times 3 \mathrm{~cm}$ mass with necrosis and hemorrhagic areas. The mass was infiltrating the ileum wall and had an ulcer on it. On microscopic examination the tumor cells were diffusely stained positive with CD117 and the Ki proliferation index was 2-4\%. Mitosis was seen less than 5 per 50 high power field (HPF) and the final diagnosis was intermediate-risk GIST. After surgery he recovered and had no recurrent bleeding episode.

\section{Case 2 (Jejunal GIST)}

A 47-year-old woman presented with intermittent hematochezia for 5 years, but the bleeding source could not be found formerly. Her hemoglobin level was $10.1 \mathrm{~g} / \mathrm{dL}$ at admission. Upper Gl endoscopy and colonoscopy with ileal intubation showed no bleeding source. Capsule endoscopy (CE) was performed and a submucosal mass was detected on jejunum (Figure 2). During the surgery, a mass was found at the distal jejunum and another mass was detected at the proximal jejunum and both of them were resected. The proximal mass was $5.5 \mathrm{~cm}$ in diameter with no mitosis per $50 \mathrm{HPFs}$ and the distal mass was $6 \mathrm{~cm}$ with 4 mitosis per $50 \mathrm{HPFs}$. After operation, the patient recovered completely with no symptoms.

\section{Case 3 (Duodenal GIST)}

A 42-year-old woman presented with fatigue and melena for 5 days. She had no prior medical history or medication. The hemoglobin level was $7.0 \mathrm{~g} / \mathrm{dL}$ at admission. By upper $\mathrm{Gl}$ endoscopy, a hyperemic submucosal mass was located on the posterior wall of the bulbus and no other potential bleeding source was observed. Abdominal CT showed an 18x15 $\mathrm{mm}$ smooth mass growing in to the lumen (Figure 3). GIST was the preliminary diagnosis and duodenotomy was performed. Pathologic examination confirmed the diagnosis of low-risk GIST with no mitosis per 50 HPFs. After surgery the patient remained well and symptom-free. 


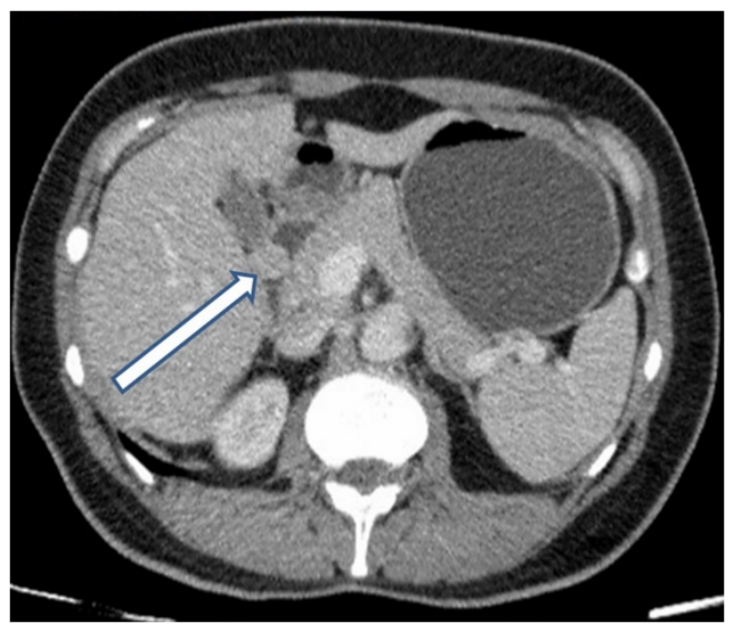

Figure 3: Abdominal CT demonstrating a smooth mass (arrow) growing into the lumen

Table 1: Clinical characteristics of the patients

\begin{tabular}{cccccc}
\hline & Age & Presenting Symptom & Presenting Hemoglobin Level & GIST Localisation & Diagnosis Modality \\
\hline Case 1 & 29 & Hematochezia & $6.8 \mathrm{~g} / \mathrm{dL}$ & Distal Ileum & Magnetic Resonance Enterography \\
\hline Case 2 & 47 & Hematochezia & $10.1 \mathrm{~g} / \mathrm{dL}$ & Jejunum & Capsule Endoscopy \\
\hline Case 3 & 42 & Fatigue and melena & $7.0 \mathrm{~g} / \mathrm{dL}$ & Duodenal bulbus & Upper GI Endoscopy \\
\hline
\end{tabular}

GIST: Gastrointestinal stromal tumor

The clinical findings and diagnosis of the cases are summarized in Table 1.

\section{DISCUSSION}

Here we present 3 cases with intestinal GISTs whose diagnosis were made with three different diagnostic methods. All the patients presented with active GI bleeding symptoms and after diagnosis successful surgery was performed.

GISTs are the most common mesenchymal tumors of the GI tract. They compose of spindle cells, epitelioid, or pleomorphic mesenchymal cells and mostly express the KIT (CD117 stem cell factor receptor) protein (5). Before 1970s, GIST were named as leiomyomas (benign) or leiomyosarcomas (malign), because they were thought to originate from smooth muscle cells (6). But immunohistochemical and electron microscopic findings revealed that GISTs are different from leiomyomas and leiomyosarcomas. In 1983 Mazur and Clark defined "gastric stromal tumors" as leiomyomas which do not exhibit ultrastructural characteristics of smooth muscle cells and lack immunohistochemical features of Schwann cells (7). Cajal cells, which are located in the submucosal and myenteric plexus of the $\mathrm{Gl}$ tract, were described to be the common origin (1). After all, the term GIST was applied to the mesenchymal tumors arising in the submucosa of the GI tract (5).

GISTs represent $80 \%$ of mesenchymal GI tumors and $0.1-3 \%$ of all GI malignancies $(2,3)$. The incidence of GIST is estimated to be 10-20/million (5). GISTs are mostly located in the stomach, followed by the intestine, colon and rectum and esophagus $(5,6)$. The median age of individuals are around 55-65 years and GISTs rarely develop under the age of 40 years (8). Our patients' mean age was 39.3 years, which is relatively low for patients with GIST.

The clinical findings of GISTs are various, and about $70 \%$ of the patients have symptoms $(4,8)$. Bleeding is one of the most common symptoms and occurs due to the erosion of GI tract lumen (4). GI bleeding is seen in about $30 \%$ of patients (6), and patients may present with hematochezia, hematemesis, melena or anemia without symptoms (4). The degree of Gl bleeding varies from asymptomatic chronic bleeding and unexplained anemia to massive life-threatening hemorrhage. Significant acute bleeding is an unusual finding (9). Here we presented 3 patients with intestinal GISTs and all patients presented with $\mathrm{GI}$ tract bleeding with a mean hemoglobin level of $7.97 \mathrm{~g} / \mathrm{dL}$. Two of the patients, who had GIST originating from jejunum and ileum had hematochezia whereas the patient with duodenal GIST presented with melena. All patients recovered completely after surgery.

GISTs can be seen as a submucosal protuberance, commonly with a central ulceration on endoscopic techniques. EUS can be useful in the diagnosis of gastric GIST since it differentiates the different layers of the gastric wall, and biopsy is not mandatory prior to surgery (5). CT scan of GISTs exhibits exophytic growing hypervascular tumors and enhance inhomogeneously $(10,11)$. The diagnosis was made with upper $\mathrm{Gl}$ endoscopy and CT in the patient with duodenal GIST. Intestinal diseases causing Gl bleeding, which are beyond the reach of upper endoscopy, are difficult to diagnose. 
Double-balloon enteroscopy and CE can identify intestinal lesions causing obscure Gl bleeding $(12,13)$. A study which included 12 cases of intestinal GISTs, showed that the double-balloon enteroscopy and the combination of CE and CT were useful imaging modalities for detecting the tumor (12). CE is an effective tool for localizing obscure Gl bleeding, but it was also recorded that it can miss even large masses (14). In one study evaluating the effectiveness of CE in small bowel tumors, Zagorowicz et al. found 3 small bowel GISTs in 150 CE investigations. During the follow up period 2 more GISTs were found, which had not been detected on CE (15). Similarly, in the present report, one of GISTs was detected on $C E$, but the patient had two lesions and only one of them was seen on CE. In our case series the ileal GIST was detected on MRE, which is not widely used for this indication. MRE may be used in the diagnostic approach to reveal obscure GI bleeding. In a prospective trial evaluating MRE for mesenteric small-bowel tumors in 75 patients with suspected smallbowel tumors, 37 intestinal tumors in 26 patients were detected. Among these patients 3 patients had GISTs in jejunum and ileum. The sensitivity of MRE for mesenteric small-bowel tumors was found $96 \%$ on per-patient and $70 \%$ on perlesion basis (16).

In conclusion, here we have presented 3 cases of intestinal GISTs with active bleeding, which is seen rarely in clinical practice. The diagnoses of these patients were made with upper GI endoscopy, CT, CE and MRE. Intestinal GIST should be kept in mind in patients with Gl bleeding of unknown origin and these different diagnostic modalities can be used to detect the source of bleeding.

\section{REFERENCES}

1. Hirota S, Isozaki K, Moriyama $Y$, et al. Gain-of-function mutations of c-kit in human gastrointestinal stromal tumors. Science 1998;279(5350):577-80. https://doi.org/10.1126/science.279.5350.577 PMid:9438854

2. Caterino S, Lorenzon L, Petrucciani N, et al. Gastrointestinal stromal tumors: correlation between symptoms at presentation, tumor location and prognostic factors in 47 consecutive patients. World J Surg Oncol 2011;9:13. https://doi.org/10.1186/1477-7819-9-13 PMid:21284869 PMCid:PMC3039617

3. DeMatteo RP, Lewis JJ, Leung D, Mudan SS, Woodruff JM, Brennan MF. Two hundred gastrointestinal stromal tumors: recurrence patterns and prognostic factors for survival. Ann Surg 2000;231(1):51-8. https://doi.org/10.1097/00000658-200001000-00008 PMid:10636102 PMCid:PMC1420965

4. Stamatakos M, Douzinas E, Stefanaki C, et al. Gastrointestinal stromal tumor. World J Surg Oncol 2009;7:61. https://doi.org/10.1186/1477-7819-7-61 PMid:19646278 PMCid:PMC2749031

5. Beham AW, Schaefer IM, Schüler P, Cameron S, Ghadimi BM. Gastrointestinal stromal tumors. Int J Colorectal Dis 2012;27(6):689-700. https://doi.org/10.1007/s00384-011-1353-y PMid:22124674 PMCid:PMC3359441

6. Degrate L, Nobili C, Garancini $M$, et al. Challenging diagnosis of ileal gastrointestinal stromal tumor presenting with obscure digestive bleeding. Tumori 2009:95(6):823-7. https://doi.org/10.1177/030089160909500630 PMid:20210252

7. Mazur MT, Clark HB. Gastric stromal tumors. Reappraisal of histogenesis. Am J Surg Pathol 1983;7(6):507-19. https://doi.org/10.1097/00000478-198309000-00001

8. Kim KM, Kang DW, Moon WS, et al. Gastrointestinal stromal tumors in Koreans: it's incidence and the clinical, pathologic and immunohistochemical findings. J Korean Med Sci 2005;20(6):977-84. https://doi.org/10.3346/jkms.2005.20.6.977 PMid:16361808 PMCid:PMC2779330

9. Machado NO, Chopra PJ, Al-Haddabi IH, Al-Qadhi H. Large duodenal gastrointestinal stromal tumor presenting with acute bleeding managed by a whipple resection. A review of surgical options and the prognostic indicators of outcome. JOP 2011:12(2):194-9. PMid:21386652

10. Sandrasegaran K, Rajesh A, Rushing DA, Rydberg J, Akisik FM, Henley JD. Gastrointestinal stromal tumors: CT and MRI findings. Eur Radiol 2005;15(7):1407-14. https://doi.org/10.1007/s00330-005-2647-7 PMid:15761716

11. Cai PQ, Lv XF, Tian L, et al. CT Characterization of Duodenal Gastrointestinal Stromal Tumors. AJR Am J Roentgenol 2015;204(5):988-93. https://doi.org/10.2214/AJR.14.12870 PMid:25905932

12. Nakatani $M$, Fujiwara $Y$, Nagami $Y$, et al. The usefulness of double-balloon enteroscopy in gastrointestinal stromal tumors of the small bowel with obscure gastrointestinal bleeding. Intern Med 2012;51(19):2675-82. https://doi.org/10.2169/internalmedicine.51.7847 PMid:23037455

13. Calabrese C, Gionchetti P, Calafiore A, Pagano N, Campieri M, Rizzello F. Sporadic small bowel tumors detected by capsule endoscopy in patients with occult gastrointestinal bleeding. Intern Emerg Med 2015;10(7):781-5. https://doi.org/10.1007/s11739-015-1314-5 PMid:26350281 
14. Mavrogenis $G$, Coumaros $D$, Renard $C$, et al. Jejunal gastrointestinal stromal tumor missed by three capsule endoscopies. Endoscopy. 2011;43(8):735-6;author reply 737. https://doi.org/10.1055/s-0030-1256573 PMid:21811941

15. Zagorowicz ES, Pietrzak AM, Wronska E, et al. Small bowel tumors detected and missed during capsule endoscopy: Single center experience. World J Gastroenterol 2013;19(47):9043-8. https://doi.org/10.3748/wjg.v19.i47.9043 PMid:24379629 PMCid:PMC3870557

16. Amzallag-Bellenger $E$, Soyer $P$, Barbe $C$, Diebold MD, Cadiot $G$, Hoeffel C. Prospective evaluation of magnetic resonance enterography for the detection of mesenteric small bowel tumours. Eur Radiol 2013;23(7):1901-10. https://doi.org/10.1007/s00330-013-2800-7 PMid:23479221

$\diamond \diamond \diamond \diamond \diamond \diamond \diamond$

http://www.ejgm.co.uk 